\title{
Relative risk of pulmonary embolism in the very elderly compared with the elderly
}

\author{
This article was published in the following Dove Press journal: \\ Clinical Interventions in Aging \\ 10 July 2013 \\ Number of times this article has been viewed
}

\section{Josef Yayan}

Department of Internal Medicine, University Hospital of Saarland, Homburg/Saar, Germany
Correspondence: Josef Yayan

Department of Internal Medicine,

University Hospital of Saarland,

Kirrberger Straße, D-6642I Homburg/

Saar, Germany

Tel +49684 II 62 I620

Fax +49684 II623602

Email josef.yayan@hotmail.com
Background: Pulmonary embolism (PE) can be an acute, life-threatening emergency, and studies suggest that advanced age is a risk factor for this condition. However, the literature is scarce regarding PE in patients above the age of 90 years. This study examined the relative risk for PE in the very elderly ( $>90$ years) compared with that in the elderly (80-89 years).

Methods: A retrospective study was performed examining very elderly patients diagnosed with PE in the Department of Internal Medicine at the University Hospital Homburg/Saar in Germany between 2004 and 2012. Elderly patients (aged 80-89 years) diagnosed with PE served as controls. PE was confirmed by contrast-enhanced chest computed tomography or ventilation perfusion scintigraphy in both groups. A total of 2230 patients were examined for PE in this study. Of these, $15(0.67 \%)$ in the study group and $197(8.83 \%)$ in the control group underwent further evaluation for PE.

Results: After performing a radiological examination, 11 (73.3\%, including six [54.55\%] women) of the 15 study patients (mean age $91.6 \pm 1.67$ years) and 148 (75.1\%, including $93[62.84 \%$ ] women) of the 197 controls (mean age $84.0 \pm 2.59$ years) were confirmed to have PE. There was a significantly lower proportion of the very elderly enrolled in the study $(P<0.001)$. There were no significant differences in clinical presentation, cardiovascular risk factors, electrocardiograms, blood gas analyses, radiological diagnoses, or acute comorbidities between the groups. However, the very elderly were more likely to experience minor bleeding in the extremities $(P=0.016)$ and to have more chronic diseases $(P<0.001)$. An increased relative risk of $\mathrm{PE}$ was not detected in the very elderly (relative risk $0.98, P=0.88$ ). Furthermore, D-dimer, troponin $\mathrm{T}$, and high-sensitive troponin $\mathrm{T}$ levels had limited predictive value for $\mathrm{PE}$ in the very elderly. There were no significant differences in the number of hospital admissions, intensive care or ward treatments, or duration of hospitalization.

Conclusion: The relative risk for PE in the very elderly is not higher than that in the elderly. Keywords: embolism, aging, electrocardiography, morbidity, risk factors

\section{Introduction}

Pulmonary embolism (PE) occurs when the main pulmonary artery or one of its branches suddenly closes due to the presence of a thrombus deported from elsewhere in the body, usually the deep veins of the leg. ${ }^{1}$ A small proportion of PEs are caused by fat, air, bone marrow, amniotic fluid, or septic substances. ${ }^{1}$ If not quickly treated, PE can be life-threatening. ${ }^{2}$ After myocardial infarction and cerebrovascular disease, PE is the third leading cause of death. ${ }^{3}$ Unfortunately, it is also among the least accurately diagnosed acute emergency diseases. ${ }^{3}$

The incidence of PE rises significantly with age, according to some hypotheses from recent studies. ${ }^{2}$ In the elderly, diagnosing PE can be difficult due to the extensive 
number of cardiopulmonary conditions that may mimic the clinical presentation of $\mathrm{PE}$ in this population. ${ }^{2}$ Diagnosis of PE relies on clinical likelihood, serum D-dimer levels, compression ultrasonography of the lower limb, ventilationperfusion lung scans, and/or helical computed tomography (CT). ${ }^{2}$ Pulmonary angiography is seldom required because noninvasive diagnostic tests are generally sufficient. ${ }^{2}$ Further, age can affect and confound the diagnostic tests for PE. ${ }^{2}$ With increasing age, the predictive values of D-dimer and ventilation-perfusion lung scan are reduced. ${ }^{2}$ Exclusion of $\mathrm{PE}$ in patients older than 80 years by assessment of the D-dimer level is possible in only $5 \%$ of patients. ${ }^{2}$ However, age has no effect on the diagnostic precision of lower limb compression ultrasonography and helical CT. ${ }^{2}$ Therefore, a rational diagnostic approach to $\mathrm{PE}$ in the elderly should rely mainly on investigations that are meaningful and have both high sensitivity and specificity. ${ }^{2}$

The objective of this study was to compare the clinical presentation, cardiovascular risk factors, acute and chronic comorbidities, electrocardiographic changes, blood gas analyses, and radiologic imaging studies between the very elderly (aged $>90$ years) and elderly (aged 80-89 years) with a diagnosis of $\mathrm{PE}$. This investigation was designed to acquire new insights into the accurate and prompt diagnosis of this acute emergency disease. Specifically, we examined whether there is an increased risk of PE in the very elderly population; whether the very elderly demonstrate an increased number of PEs; and whether PE diagnoses in the very elderly population can be made based on clinical symptoms, D-dimer values, electrocardiographic changes, blood gas analyses, and radiologic imaging.

\section{Materials and methods Patients}

A retrospective study was performed using the medical records of patients treated for PE at the Department of Internal Medicine of the University Hospital Homburg/Saar in Germany between 2004 and 2012. The highest possible decade of life was used in this study, with the assumption that the highest life expectancy is, on average, 100 years of age. The two possible last decades of highest life used for comparison were close together to prevent any distortion in the data analysis due to age. Therefore, the study population was comprised of very elderly (aged $>90$ years) patients diagnosed with PE, and the controls were elderly patients (aged 80-89 years) with $\mathrm{PE}$. The relative risk of developing $\mathrm{PE}$ was assessed as a ratio of the probability of PE occurring to the probability of PE not occurring among patients in both groups. Clinical symptoms of
PE considered were dyspnea, chest pain, cough, hemoptysis, tachypnea, jugular venous distension, cyanosis, hypotension, and shock. The diagnosis of PE was made according to the latest edition of the International Classification of Disease (ICD I26.0-I26.9) from 2004 to 2012. PE was further defined as central or peripheral, depending on the location or arterial branch involved. Central vascular zones included the main pulmonary artery, the left and right main pulmonary arteries, the anterior trunk, the right and left interlobar arteries, the left upper lobe trunk, the right middle lobe artery, and the right and left lower lobe arteries. Peripheral vascular zones comprised the segmental and subsegmental arteries. A PE was considered massive when it involved both pulmonary arteries or resulted in hemodynamic compromise.

Clinical presentation of the patients in the emergency room was determined upon admission or hospital transfer. Acute and chronic comorbidities considered included cardiovascular, pulmonary, gastrointestinal tract, renal, urogenital, gynecological, neurological, psychiatric, orthopedic, dermatological, and allergic diseases. Plasma D-dimer concentrations were measured in citrated blood $(1+10$ mixture of $3.5 \%$ aqueous sodium citrate and blood; Sarstedt, Nümbrecht, Germany) using a well validated, commercial, particle-enhanced, immunoturbidimetric assay (Innovance ${ }^{\circledR}$ D-dimer, Siemens Medical Solutions, Erlangen, Germany) with the Behring Coagulation System analyzer (Dade Behring, Marburg, Germany). Highly sensitive troponin $\mathrm{T}$ levels were measured using the Elecsys ${ }^{\circledR}$ troponin $\mathrm{T}$ electrochemiluminescence immunoassay (fourth-generation) with the Roche Elecsys 2010 analyzer (Hoffman-La Roche Ltd, Mannheim, Germany). In addition to highly sensitive troponin T levels, conventional troponin T levels (Stat T, Roche Diagnostics, Mannheim, Germany) were measured using an electrochemiluminescence immunoassay (thirdgeneration) on an Elecsys 2010 platform (Roche). D-dimer, troponin $\mathrm{T}$, and highly sensitive troponin $\mathrm{T}$ were ordered as necessary (normal $<0.5 \mathrm{mg} / \mathrm{L},<0.10 \mathrm{ng} / \mathrm{mL},<50 \mathrm{pg} / \mathrm{mL}$, respectively). The 12-lead electrocardiogram was evaluated for sinus rhythm, atrial fibrillation, and tachyarrhythmia absoluta in atrial fibrillation, T negativity, and S1Q3 changes suggestive of PE. Arterial or venous blood gas analyses were performed as soon as possible to support an early diagnosis of PE. Lower limb ultrasonography was used to detect deep venous thrombosis as a possible etiology for PE. Contrastenhanced chest $\mathrm{CT}$ and/or ventilation perfusion scintigraphy were used to confirm the diagnoses of PE in each group. The presence of cor pulmonale with PE was determined using echocardiography in all patients. 
The medical treatment of both groups was also compared, along with hospital admissions, number of treatments in intensive care or general wards, and length of hospitalization. Numerical trends for PE in recent years were examined for both groups. Finally, the number of reanimations and autopsies as well as the mortality rate were calculated for both groups. Due to the retrospective nature of the study protocol, the Medical Association of Saarland's Institutional Review Board waived the need for informed consent.

\section{Statistical analysis}

Relative risk and 95\% confidence intervals (CIs) were calculated and compared between the very elderly and the elderly. The chi-square test was used to compare any differences in gender, clinical presentation, cardiovascular risk factors, acute and chronic comorbidities, D-dimer values, troponin $\mathrm{T}$, high sensitive troponin $\mathrm{T}$, electrocardiogram, hospital admissions, number of intensive care or ward treatments, recurrent PE, recurrent deep vein thrombosis, and location of PE (central versus peripheral). The Mann-Whitney test was used to calculate the differences in age, duration of hospitalization, D-dimer levels, and total chronic disease profiles. All results are expressed as the mean and standard deviation. Survival rates for both groups were calculated using the Kaplan-Meier method. $P<0.05$ was considered to be statistically significant.

\section{Results}

From the total of 2230 patients evaluated for PE during the study period, $15(0.67 \%)$ patients were assigned to the study group and 197 (8.83\%) patients were assigned to the control group. Eleven (including six [54.55\%] women) of the 15 study patients $(73.3 \%, 95 \%$ CI 51.0-95.7) and 148 (including $93[62.84 \%]$ women) of the 197 control patients $(75.1 \%$, 95\% CI 69.1-81.2) were diagnosed with PE. Compared with the elderly, there was no increase in relative risk for $\mathrm{PE}$ in the very elderly $(0.98,95 \% \mathrm{CI} 0.72-1.34, P=0.88)$. There was a significant difference in the number of cases between the two groups during the study period $(P=0.0003$, Figure 1). The mean age of the patients in the study group was $91.6 \pm 1.67$ years compared with $84.0 \pm 2.59$ years in the control group $(P<0.0001)$. There was no significant difference in gender ratio between the two groups $(P=0.584)$. There were also no significant differences in the diagnostic procedures, clinical features of PE subtypes, and medical therapy administered (Table 1). The study group was more likely to experience minor bleeding at the extremities $(P=0.016$, Table 2$)$. There was no significant difference in cardiovascular risk factors (Table 3). Multiple significant differences were found in chronic comorbidities between the two groups $(P<0.001$, Table 4$)$. Pulmonary embolism $(P=0.365)$ and recurrences of deep vein thrombosis $(P=0.64)$ were detected in the two groups but without any statistically significant differences (Table 4). The mean D-dimer value was $9.24 \pm 12.8 \mathrm{mg} / \mathrm{L}$ (range $0.4-34.9 \mathrm{mg} / \mathrm{L}$; mode $0.4 \mathrm{mg} / \mathrm{L}$ ) in the study group and $5.57 \pm 7.73 \mathrm{mg} / \mathrm{L}$ (range $0.2-34.9 \mathrm{mg} / \mathrm{L}$; mode $0.5 \mathrm{mg} / \mathrm{L}$ ) in the control group (Figure 2); this difference was not statistically significant $(P=0.67)$. In the study group, there were four positive, four negative, and three indeterminate D-dimer results. In comparison, there

\section{Trends of pulmonary embolism}

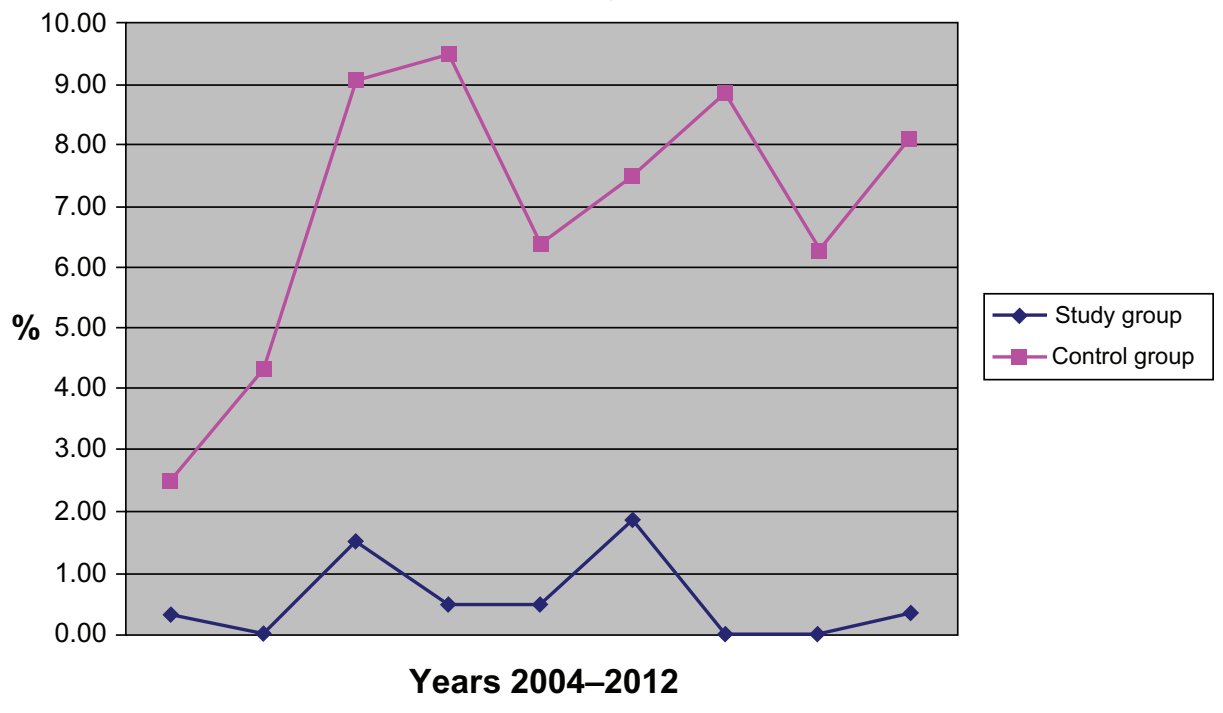

Figure I Trends in rates of pulmonary embolism in the very elderly and elderly. 
Table I Comparison of clinical presentation, diagnosis, and treatment for pulmonary embolism in the study and control groups

\begin{tabular}{|c|c|c|c|}
\hline & $\begin{array}{l}\text { Study group } \\
(\mathbf{n}=\text { I I ) } \\
(\%)^{*}\end{array}$ & $\begin{array}{l}\text { Control group } \\
(n=148) \\
(\%)^{*}\end{array}$ & $P$ value \\
\hline \multicolumn{4}{|l|}{ Electrocardiogram } \\
\hline Sinus rhythm & $10(91)$ & $91(6 \mathrm{I})$ & 0.051 \\
\hline Sinus tachycardia & 0 & $20(14)$ & 0.192 \\
\hline $\begin{array}{l}\text { Tachyarrhythmia } \\
\text { absoluta in atrial } \\
\text { fibrillation }\end{array}$ & I (9) & $8(5)$ & $0.6 \mathrm{I}$ \\
\hline Atrial fibrillation & 0 & $27(18)$ & 0.12 \\
\hline Atrial flutter & 0 & $2(1)$ & 0.698 \\
\hline T-negativity & $3(27)$ & $24(16)$ & 0.346 \\
\hline SIQ3 & I (9) & II (7) & 0.841 \\
\hline Pacemaker & I (9) & $3(2)$ & 0.149 \\
\hline \multicolumn{4}{|l|}{ Clinical symptoms } \\
\hline Dyspnea & $5(45)$ & $83(56)$ & 0.494 \\
\hline Chest pain & I (9) & $31(2 \mid)$ & 0.344 \\
\hline Cough & 0 & $9(6)$ & 0.4 \\
\hline Hemoptysis & 0 & 0 & 1.0 \\
\hline Tachypnea & 0 & 0 & 1.0 \\
\hline Cervical venous & 0 & I (I) & 0.785 \\
\hline \multicolumn{4}{|l|}{ obstruction } \\
\hline Hypotension & 0 & $10(7)$ & 0.373 \\
\hline Shock & 0 & $10(7)$ & 0.373 \\
\hline Cyanosis & 0 & $4(3)$ & 0.581 \\
\hline \multicolumn{4}{|l|}{ Blood gas analysis } \\
\hline Hyperoxia & I (9) & $13(9)$ & 0.972 \\
\hline Hypoxia & $4(36)$ & $78(53)$ & 0.296 \\
\hline Hypercapnia & 0 & 0 & 1.0 \\
\hline \multicolumn{4}{|l|}{ Imaging modality } \\
\hline $\begin{array}{l}\text { Chest computed } \\
\text { tomography }\end{array}$ & $9(2 \mathrm{I})$ & |3| (89) & 0.509 \\
\hline $\begin{array}{l}\text { Ventilation perfusion } \\
\text { scintigraphy }\end{array}$ & $2(18)$ & II (7) & 0.209 \\
\hline Echocardiography & $3(27)$ & $74(50)$ & 0.146 \\
\hline $\begin{array}{l}\text { Venous duplex } \\
\text { ultrasound, legs }\end{array}$ & $8(73)$ & $100(68)$ & 0.724 \\
\hline \multicolumn{4}{|l|}{ Clinical diagnosis } \\
\hline $\begin{array}{l}\text { Deep vein } \\
\text { thrombosis, right }\end{array}$ & $4(36)$ & $40(27)$ & 0.504 \\
\hline $\begin{array}{l}\text { Deep vein } \\
\text { thrombosis, left }\end{array}$ & $3(27)$ & $26(18)$ & 0.421 \\
\hline \multicolumn{4}{|c|}{ Location of pulmonary embolism } \\
\hline Central right & 0 & $23(16)$ & 0.157 \\
\hline Central left & 0 & $8(5)$ & 0.429 \\
\hline Fulminant & $2(18)$ & $28(19)$ & 0.952 \\
\hline Peripheral right & $5(45)$ & $62(42)$ & 0.817 \\
\hline Peripheral left & $2(18)$ & $46(3 I)$ & 0.369 \\
\hline Segmental & $2(18)$ & $18(12)$ & 0.561 \\
\hline \multicolumn{4}{|l|}{ Hemodilution treatment } \\
\hline Full heparinization & $3(27)$ & $6 I(4 I)$ & 0.363 \\
\hline Low molecular heparin & $8(73)$ & $99(67)$ & 0.691 \\
\hline Warfarin & $7(64)$ & $70(47)$ & 0.296 \\
\hline Argatroban & 0 & $2(1)$ & 0.698 \\
\hline Alteplase & 0 & $4(3)$ & $0.58 \mathrm{I}$ \\
\hline
\end{tabular}

Note: *Rounded to whole numbers.
Table 2 Acute comorbidities in the study and control groups

\begin{tabular}{|c|c|c|c|}
\hline Acute comorbidities & $\begin{array}{l}\text { Study group } \\
(n=I I) \\
(\%)^{*}\end{array}$ & $\begin{array}{l}\text { Control group } \\
(\mathrm{n}=148) \\
(\%)^{*}\end{array}$ & $P$ value \\
\hline Cor pulmonale & $4(36)$ & $39(26)$ & 0.471 \\
\hline Cardiac decompensation & $3(27)$ & $15(10)$ & 0.084 \\
\hline Syncope & $2(18)$ & $18(12)$ & 0.561 \\
\hline Hypertensive derailment & 0 & $7(5)$ & $0.46 \mathrm{I}$ \\
\hline Circulatory collapse & 0 & $4(3)$ & 0.581 \\
\hline Hypotension & 0 & $8(5)$ & 0.429 \\
\hline Acute coronary syndrome & 0 & $I(I)$ & 0.785 \\
\hline Thrombocytopenia & 0 & $3(2)$ & 0.634 \\
\hline $\begin{array}{l}\text { Heparin-induced } \\
\text { thrombocytopenia }\end{array}$ & 0 & $3(2)$ & 0.634 \\
\hline Atrial thrombus & 0 & $4(3)$ & 0.581 \\
\hline Sepsis & 0 & $9(6)$ & 0.4 \\
\hline $\begin{array}{l}\text { Takotsubo } \\
\text { cardiomyopathy }\end{array}$ & 0 & $I(I)$ & 0.785 \\
\hline Bradycardia & 0 & $2(I)$ & 0.699 \\
\hline Anemia & I (9) & $16(11)$ & 0.859 \\
\hline Bleeding in extremities & I (9) & I (I) & 0.016 \\
\hline $\begin{array}{l}\text { Bronchopulmonary } \\
\text { infection }\end{array}$ & I (9) & $6(4)$ & 0.432 \\
\hline Pneumonia & 0 & $26(18)$ & 0.129 \\
\hline Pulmonary edema & 0 & $4(3)$ & $0.58 \mathrm{I}$ \\
\hline Pleural effusion & 0 & $12(8)$ & 0.326 \\
\hline Lung atelectasis & 0 & $6(4)$ & 0.496 \\
\hline $\begin{array}{l}\text { Gastrointestinal } \\
\text { hemorrhage }\end{array}$ & I (9) & $8(5)$ & 0.610 \\
\hline Gastritis & I (9) & $12(8)$ & 0.909 \\
\hline Esophagitis & I (9) & $6(4)$ & 0.432 \\
\hline Glucose derailment & 0 & $I(I)$ & 0.785 \\
\hline Ileus & 0 & $2(1)$ & 0.698 \\
\hline Gastric ulcer & 0 & $4(3)$ & $0.58 \mathrm{I}$ \\
\hline Cholangitis & 0 & $3(2)$ & 0.634 \\
\hline Constipation & 0 & $6(4)$ & 0.496 \\
\hline Diarrhea & 0 & $4(3)$ & 0.581 \\
\hline Ascites & 0 & $I(I)$ & 0.785 \\
\hline $\begin{array}{l}\text { Acute urinary tract } \\
\text { infection }\end{array}$ & I (9) & $15(10)$ & 0.912 \\
\hline Acute renal failure & 0 & $17(11)$ & 0.234 \\
\hline Overflow incontinence & 0 & $4(3)$ & $0.58 \mathrm{I}$ \\
\hline Anuria & 0 & $4(3)$ & 0.581 \\
\hline Electrolyte disturbance & 0 & $10(7)$ & 0.373 \\
\hline Hematuria & 0 & $2(I)$ & 0.698 \\
\hline Mental confusion & 0 & $I(I)$ & 0.785 \\
\hline Vaginal thrush & 0 & $I(I)$ & 0.785 \\
\hline Contusion & 0 & $5(3)$ & 0.536 \\
\hline Exsiccosis & 0 & $8(5)$ & 0.429 \\
\hline Erysipelas & 0 & $2(1)$ & 0.698 \\
\hline Reanimation & 0 & I (I) & 0.785 \\
\hline Delirium & 0 & $3(2)$ & 0.634 \\
\hline Somnolence & 0 & I (I) & 0.785 \\
\hline
\end{tabular}

Notes: *Rounded to whole numbers; Significant $P$ value shown in bold.

were 87 positive, 23 negative, and 38 indeterminate D-dimer results in the control group. Therefore, the D-dimer level does not have a significant predictive value in the very elderly $(P=0.059)$. All seven troponin tests drawn in the study group were negative. Of the 96 troponin tests drawn in the controls, 
Table 3 Cardiovascular risk factors in the study and control groups

\begin{tabular}{llll}
\hline $\begin{array}{l}\text { Cardiovascular } \\
\text { risk factors }\end{array}$ & $\begin{array}{l}\text { Study group } \\
(\mathbf{n}=\mathrm{II}) \\
(\%)\end{array}$ & $\begin{array}{l}\text { Control group } \\
(\mathbf{n}=\mathbf{I 4 8})\end{array}$ & P value \\
\hline Hypertension & $6(55)$ & $76(5 \mathrm{I})$ & \\
\hline Diabetes & $2(18)$ & $23(16)$ & 0.838 \\
Hyperlipidemia & $\mathrm{I}(9)$ & $20(14)$ & 0.816 \\
Obesity & 0 & $10(7)$ & 0.676 \\
Nicotine abuse & 0 & $10(7)$ & 0.373 \\
\hline
\end{tabular}

Note: *Rounded to whole numbers.

there were 21 positive and 75 negative results. Similar to D-dimer, troponin has limited predictive value for $\mathrm{PE}$ in the very elderly $(P=0.166)$.

None of the study patients were treated in the intensive care unit, whereas $30(20.3 \%)$ control patients were; regardless, there was no significant difference between the numbers of critical care and ward treatments $(P=0.097)$. The duration of hospitalization was not significantly different $(P=0.387)$ between the study patients (15.6 \pm 11.9 days) and control patients (12.0 \pm 10.3 days). There was no significant difference in the number of hospital admissions between the two groups $(P=0.578$, Figure 3$)$. Although there were no deaths during the study, there were $16(10.8 \%, 95 \%$ CI 5.81-15.8) deaths in the control group, including nine (59.25\%) with fatal PE; however, a statistically significant difference in fatal outcomes between the groups could not be detected $(P=0.735)$. Thus, the survival rate was $100 \%$ in the study group and $89.2 \%$ (95\% CI 83.9-94.5) in the control group.

\section{Discussion}

This study did not find an increased relative risk for PE in the very elderly compared with the elderly. PEs are common among the elderly, ${ }^{3}$ but are the least often accurately diagnosed cardiovascular disease. ${ }^{3}$ The annual incidence rates for PE and deep vein thrombosis have been reported to increase steadily with advancing age. ${ }^{4}$ However, there was a significantly lower proportion of very elderly patients enrolled in this study, and these patients did not demonstrate an increased incidence of PE compared with the elderly population. Moreover, no increased relative risk for PE was detected in the very elderly. Women have also been reported to have lower rates of PE compared with men, ${ }^{4}$ but both groups in this study contained more affected women, with no statistically significant difference found between the groups. These findings could be due to the small size of the study group and because of the study being conducted in a single department. Further, numbers of patients become smaller with advancing biological age. Recurrent PEs were observed, but with no statistically significant difference in rate of recurrence between the two groups during this investigation.

Risk factors for PE include congestive heart failure, cancer, orthopedic conditions such as hip fracture, and other debilitating diseases. ${ }^{5}$ We observed an increased prevalence of congestive heart failure among the very elderly, but the difference relative to the elderly population was not statistically significant. Further, using the example of renal tumors, cancer among those of very advanced age was not observed in this study. Bone disorders were found to be significantly more prevalent among the very elderly than in the elderly. There were other multiple chronic diseases affecting a significantly higher proportion of the very elderly in this study.

The most commonly reported comorbidities in elderly patients with PE are cardiomegaly (22\%-64\%), pleural effusion (15.8\%-57\%), right heart overload (50\%), syncope (8\%-62\%), shock (5\%-31\%), cough ( $12 \%-43 \%)$, hemoptysis $(3 \%-14 \%)$, deep vein thrombosis $(15 \%-50 \%)$, cancer $(4 \%-32 \%)$, surgery $(5 \%-44 \%)$, heart failure $(5 \%-33 \%)$, previous deep vein thrombosis or PE $(18 \%-41 \%)$, stroke $(3 \%-13.5 \%)$, acute myocardial infarction $(3 \%-11 \%)$, and chronic obstructive pulmonary disease $(2 \%-27 \%){ }^{6-17}$ The most acute disorders documented in our study were cor pulmonale, cardiac decompensation, syncope, minor bleeding in the extremities, bronchopulmonary infection, gastrointestinal hemorrhage, gastritis, and glucose derangement in the very elderly, but not at significantly higher rates compared with the general elderly population. There was no correlation between these acute illnesses and PE in the very elderly, with these diseases appearing to be separate entities. A number of studies have shown that elderly patients over 80 years have a higher incidence of bleeding complications. ${ }^{18}$ In our study, the very elderly had more minor bleeding complications, but we did not examine this relationship further.

The clinical presentation of PE can be subtle and atypical,${ }^{5}$ as this was also noted in our study. Traditional abnormalities in vital signs in the patient with PE can be missing, and syncope without chest pain or dyspnea is a frequent clinical symptom in the elderly. ${ }^{5}$ In our study, although not statistically significant, the very elderly were more likely to experience syncope. Therefore, the differential diagnosis of syncope in the elderly should always include PE. Previous studies have reported that the main symptoms in the elderly with PE are dyspnea (59\%-91.5\%), tachypnea (46\%-74\%), tachycardia 
Table 4 Chronic comorbidities in the study and control groups

\begin{tabular}{|c|c|c|c|c|}
\hline Organ & Chronic disease & $\begin{array}{l}\text { Study group } \\
(\mathrm{n}=\mathrm{II})(\%)^{*}\end{array}$ & $\begin{array}{l}\text { Control group } \\
(n=148)(\%)^{*}\end{array}$ & $P$ value \\
\hline \multirow[t]{12}{*}{ Heart and circulatory diseases } & Prior pulmonary embolism & I (9) & $7(5)$ & 0.365 \\
\hline & Prior deep vein thrombosis & 0 & $8(5)$ & 0.649 \\
\hline & Congestive heart failure & I (9) & $7(5)$ & 0.523 \\
\hline & Coronary heart disease & $4(36)$ & $3 I(2 I)$ & 0.234 \\
\hline & Hypertensive heart disease & I (9) & $5(3)$ & 0.337 \\
\hline & Valvular heart disease & $3(27)$ & $40(27)$ & 0.986 \\
\hline & Atrioventricular block & I (9) & $I(I)$ & 0.016 \\
\hline & Dilated cardiomyopathy & 0 & $3(2)$ & 0.634 \\
\hline & Aneurysm & 0 & $5(3)$ & 0.536 \\
\hline & State post heart attack & 0 & $21(14)$ & 0.429 \\
\hline & Peripheral arterial occlusive disease & 0 & $8(5)$ & 0.429 \\
\hline & State after syncope & 0 & $2(1)$ & 0.698 \\
\hline Total & & II & 138 & $<0.001$ \\
\hline \multirow[t]{8}{*}{ Lung diseases } & Chronic obstructive pulmonary disease & $3(27)$ & $22(15)$ & 0.275 \\
\hline & Bronchial asthma & 0 & I (2) & 0.785 \\
\hline & Obstructive sleep apnea syndrome & I (9) & $9(6)$ & 0.692 \\
\hline & Lung tumors & 0 & $15(10)$ & 0.267 \\
\hline & Pulmonary emphysema & 0 & $5(3)$ & 0.536 \\
\hline & Pulmonary fibrosis & 0 & $8(5)$ & 0.429 \\
\hline & Pulmonary tuberculosis & 0 & $4(3)$ & 0.580 \\
\hline & Pneumothorax & 0 & $\mathrm{I}(\mathrm{I})$ & 0.785 \\
\hline Total & & 4 & 65 & 0.002 \\
\hline \multirow[t]{4}{*}{ Thyroid diseases } & Hyperthyroidism & 0 & II (7) & 0.349 \\
\hline & Hypothyroidism & 0 & $3(2)$ & 0.634 \\
\hline & Struma nodosa & 0 & $5(3)$ & 0.536 \\
\hline & Strumectomy & 0 & $3(2)$ & 0.634 \\
\hline Total & & 0 & 22 & 0.021 \\
\hline \multirow[t]{3}{*}{ Liver diseases } & Chronic hepatitis B & 0 & $5(3)$ & 0.536 \\
\hline & Liver cirrhosis & 0 & $\mathrm{I}(\mathrm{I})$ & 0.785 \\
\hline & Liver metastasis & 0 & $4(3)$ & 0.581 \\
\hline Total & & 0 & 10 & 0.0495 \\
\hline \multirow[t]{3}{*}{ Gallbladder diseases } & Gallbladder stones & 0 & $5(3)$ & 0.536 \\
\hline & Cholecystectomy & 0 & $10(7)$ & 0.373 \\
\hline & Gallbladder tumors & 0 & $3(2)$ & 0.634 \\
\hline Total & & 0 & 18 & 0.0495 \\
\hline \multirow[t]{10}{*}{ Gastrointestinal diseases } & Esophageal cancer & 0 & $I(I)$ & 0.785 \\
\hline & Hernia & I (9) & $6(4)$ & 0.432 \\
\hline & Appendectomy & 0 & $5(3)$ & 0.536 \\
\hline & Colitis & 0 & $4(3)$ & 0.581 \\
\hline & Diverticulosis & 0 & II (7) & 0.349 \\
\hline & Polypectomy & 0 & $8(5)$ & 0.429 \\
\hline & Pancreatic tumors & 0 & $6(4)$ & 0.496 \\
\hline & Colon tumor & 0 & $25(17)$ & 0.138 \\
\hline & Stoma & 0 & $2(I)$ & 0.698 \\
\hline & Fecal incontinence & 0 & $3(2)$ & 0.634 \\
\hline Total & & I & 71 & $<0.001$ \\
\hline Lymphatic diseases & Non-hodgkin's lymphoma & 0 & $5(3)$ & 0.536 \\
\hline Various organs & Cystic diseases & 0 & $13(9)$ & 0.305 \\
\hline Total & & 0 & 18 & 0.121 \\
\hline \multirow[t]{7}{*}{ Urogenital disorders } & Renal insufficiency & $4(36)$ & $18(12)$ & 0.025 \\
\hline & Nephrectomy & I (9) & $\mathrm{I}(\mathrm{I})$ & 0.016 \\
\hline & Nephrolithiasis & I (9) & $2(1)$ & 0.069 \\
\hline & Kidney tumors & I (9) & $4(3)$ & 0.242 \\
\hline & Urinary incontinence & 0 & $4(3)$ & 0.581 \\
\hline & Bladder tumors & 0 & $3(2)$ & 0.634 \\
\hline & Benign prostatic hyperplasia & $4(36)$ & $20(14)$ & $0.04 I$ \\
\hline
\end{tabular}


Table 4 (Continued)

\begin{tabular}{|c|c|c|c|c|}
\hline Organ & Chronic disease & $\begin{array}{l}\text { Study group } \\
(\%)^{*}\end{array}$ & $\begin{array}{l}\text { Control group } \\
\text { (\%)* }\end{array}$ & $P$ value \\
\hline & Prostate carcinoma & 0 & $8(5)$ & 0.429 \\
\hline & Epididymitis & 0 & $I(I)$ & 0.785 \\
\hline Total & & II & 61 & 0.015 \\
\hline \multirow[t]{9}{*}{ Neurological disorders } & State post intracranial hemorrhage & I (9) & $3(2)$ & 0.149 \\
\hline & State post transient cerebral ischemia & 0 & $7(5)$ & $0.46 I$ \\
\hline & State post cerebral ischemia & 0 & $13(9)$ & 0.305 \\
\hline & Parkinson disease & 0 & $4(3)$ & $0.58 \mathrm{I}$ \\
\hline & Hydrocephalus & 0 & $2(1)$ & 0.698 \\
\hline & Polyneuropathy & I (9) & $2(1)$ & 0.069 \\
\hline & Restless legs syndrome & 0 & $I(I)$ & 0.785 \\
\hline & Meningioma & 0 & $I(1)$ & 0.785 \\
\hline & Multiple sclerosis & 0 & $I(I)$ & 0.785 \\
\hline Total & & 3 & 41 & 0.0006 \\
\hline \multirow[t]{4}{*}{ Psychiatric disorders } & Dementia & 0 & $20(14)$ & 0.192 \\
\hline & Alzheimer's disease & 0 & $2(1)$ & 0.698 \\
\hline & Depression & 0 & $5(3)$ & 0.536 \\
\hline & Various & 0 & $9(6)$ & 0.400 \\
\hline Total & & 0 & 36 & 0.021 \\
\hline Ear nose and throat diseases & Ménière's disease & I (9) & $3(2)$ & 0.149 \\
\hline \multirow[t]{6}{*}{ Gynecological diseases } & Hysterectomy & 0 & $9(6)$ & 0.400 \\
\hline & Uterine polyps & 0 & $2(1)$ & 0.698 \\
\hline & Adnexal tumor & 0 & $3(2)$ & 0.634 \\
\hline & Ovarian cancer & 0 & $I(I)$ & 0.785 \\
\hline & Breast cancer & 0 & $6(4)$ & 0.496 \\
\hline & Mastectomy & I (9) & 0 & 0.0002 \\
\hline Total & & 2 & 24 & 0.015 \\
\hline \multirow[t]{11}{*}{ Orthopedic conditions } & Hip endoprosthesis & 0 & $8(5)$ & 0.429 \\
\hline & Bone fracture & $4(36)$ & $18(12)$ & 0.025 \\
\hline & Knee replacement & 0 & $6(4)$ & 0.496 \\
\hline & Vertebral degeneration & $3(27)$ & $15(10)$ & 0.084 \\
\hline & Amputation & 0 & $2(1)$ & 0.698 \\
\hline & Rheumatism & 0 & $8(5)$ & 0.429 \\
\hline & Osteoporosis & 0 & $9(6)$ & 0.400 \\
\hline & Spinal stenosis & 0 & $5(3)$ & 0.536 \\
\hline & Herniated disc & 0 & $3(2)$ & 0.634 \\
\hline & State post fall & 0 & $10(7)$ & 0.373 \\
\hline & Plasmacytoma & 0 & I (I) & 0.785 \\
\hline Total & & 7 & 85 & 0.0003 \\
\hline Ophthalmologic diseases & Various & $4(36)$ & $14(9)$ & 0.007 \\
\hline \multirow[t]{2}{*}{ Dermatological diseases } & Various & 0 & $9(6)$ & 0.400 \\
\hline & Allergy & 0 & $4(3)$ & $0.58 \mathrm{I}$ \\
\hline Drug overdose & & 0 & $I(I)$ & 0.785 \\
\hline Autopsy & & 0 & $I(I)$ & 0.785 \\
\hline Total & & 4 & 29 & 0.037 \\
\hline Total diagnosis = I 289 & & 82 & 1207 & $<0.001$ \\
\hline
\end{tabular}

Notes: *Rounded to whole numbers; Significant $P$ values are shown in bold.

(29\%-76\%), and chest pain (26\%-59\%). ${ }^{6-17}$ In our study, dyspnea $(45 \%-56 \%)$, chest pain $(9 \%-21 \%)$, and cough $(6 \%)$ were more frequent symptoms in the very elderly and elderly, although not significantly so.

The most common electrocardiographic changes reported in previous studies included sinus tachycardia (18\%-62.5\%), right bundle branch block (4.5\%-40.5\%), ST-T abnormalities
(9\%-37\%), and S1Q3 (8\%). ${ }^{6-17}$ In this study, the most common electrocardiographic abnormalities were tachyarrhythmia absoluta in atrial fibrillation, T-negativity, and S1Q3, but these did not occur at significantly high rates compared with the elderly population. Further studies are needed to examine electrocardiographic changes in the elderly and very elderly with PE. 


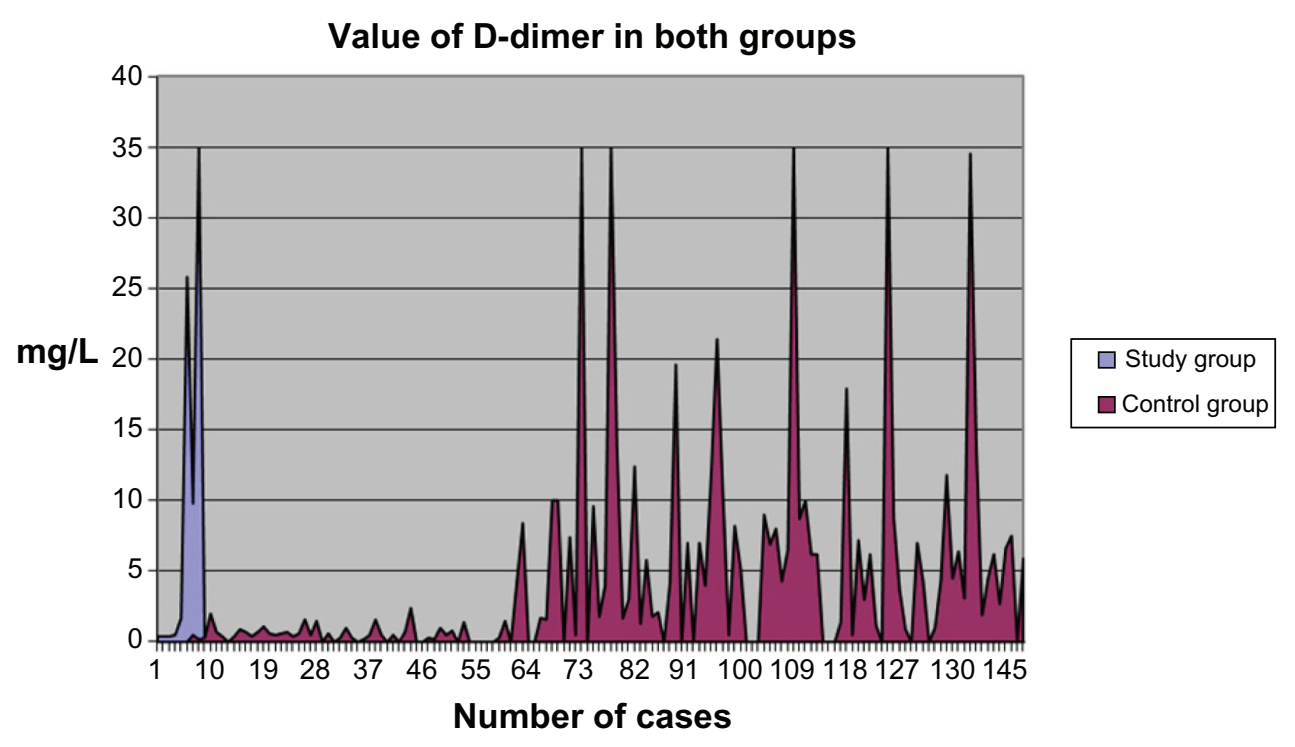

Figure 2 Comparison of D-dimer values in control and study groups.

Hypoxia has often been described in blood-gas analysis in previous studies of patients with PE. ${ }^{6,819}$ Similarly, hypoxia was frequently observed in both groups in our study, but we found no significant difference between the elderly and very elderly in this regard. Respiratory and metabolic acidosis has also been reported to be more frequent in elderly patients with
PE than in their younger counterparts.$^{6,8,19}$ However, respiratory and metabolic acidosis was not detected in either group in our study. Nevertheless, we noted hypoxia in more than one third of our very elderly study patients. These respiratory changes and their implications for the diagnosis and treatment of PE require further evaluation in future prospective studies.

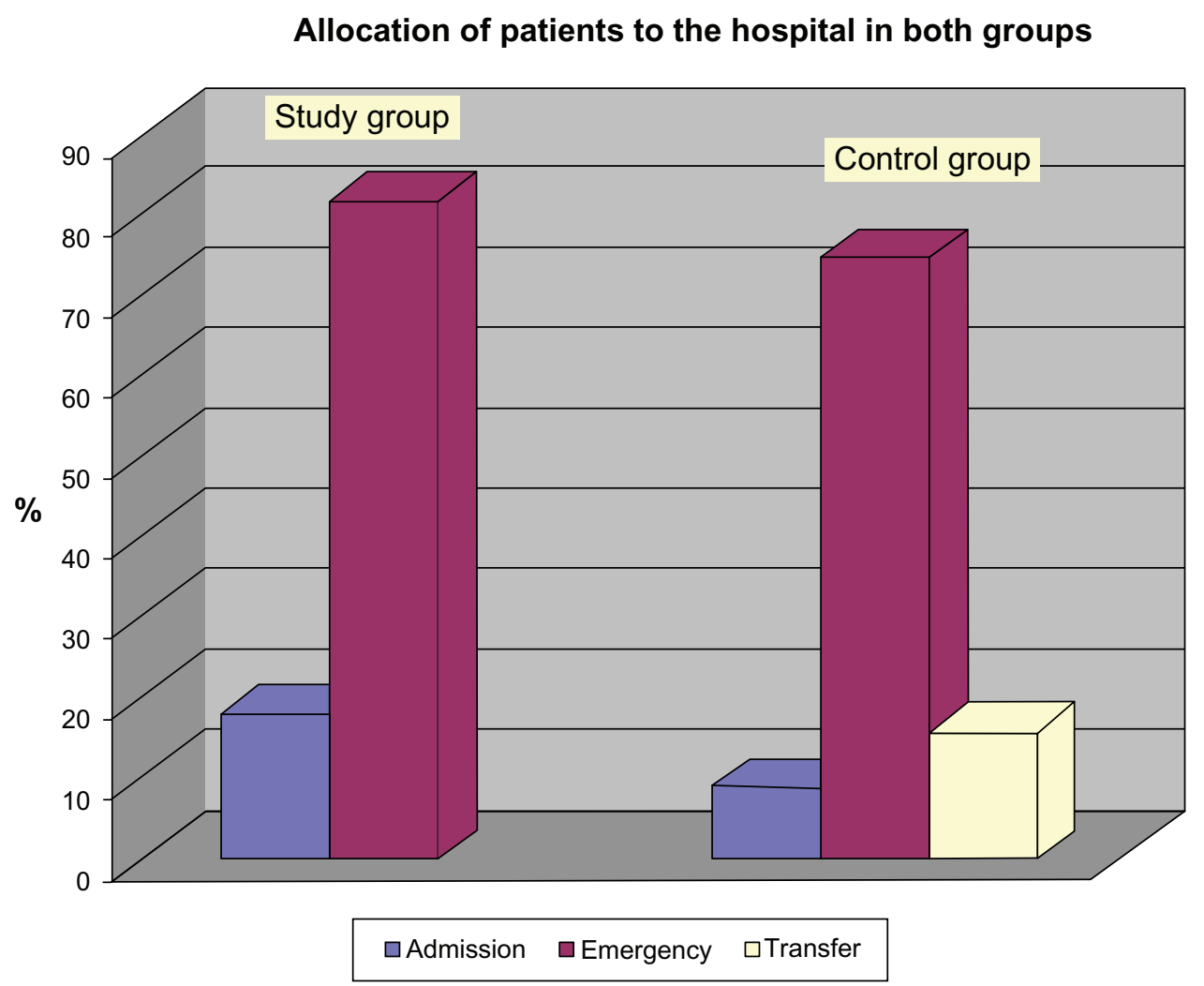

Figure 3 Comparison of hospital admissions between the control and study groups. 
The specificity of D-dimer values in patients suspected of having PE decreases with advancing age. ${ }^{20,21}$ Two studies have examined the specificity of D-dimer for diagnosis of PE in the elderly and reported similar specificities (5\%) for PE diagnosis in the elderly. ${ }^{20,21}$ This very low specificity has led to the proposal of an augmented cutoff value for D-dimer. ${ }^{6}$ An elevated cutoff would reduce the number of false positives but also increase the proportion of false negatives. ${ }^{6}$ We found a higher mean D-dimer value in the study group; however, there was no statistically significant difference in D-dimer values between the two groups. Hence, D-dimer has very limited predictive value for diagnosing PE in the very elderly.

The prognostic value of troponin has been demonstrated in high-risk patients with PE. ${ }^{22}$ Troponin can improve the risk stratification of patients with PE and help to identify patients who may require aggressive treatment. ${ }^{22,23}$ Although troponin was not routinely tested, the findings of our study suggest that troponin also has limited predictive value for PE in the very elderly. Further, we did not observe a direct relationship between PE and release of troponin.

Aging did not affect the diagnostic quality of single detector or multidetector pulmonary angio-CT for PE. ${ }^{24,25}$ Use of lung scintigraphy for diagnosing PE is limited by pre-existing lung disease or an abnormal chest radiograph. ${ }^{26,27}$ In our study, chest CT was used almost equally in both groups. Although not statistically significant, the elderly were more likely to undergo ventilation perfusion scintigraphy.

The sensitivity of Doppler ultrasound for detecting deep vein thrombosis increases with age, but not the specificity. ${ }^{27}$ Because more Doppler ultrasound examinations were performed in the very elderly in our study, more deep venous thromboses were found in this age group. Pulmonary angiography for the diagnosis of PE has the same diagnostic value in the elderly as in young age groups. ${ }^{15}$ However, this test was not available for our study, so its utility and diagnostic value cannot be commented upon.

Population-based studies have identified a greater risk of death from PE in the elderly. ${ }^{28}$ The mortality rates in this study were surprising, in that there were more deaths observed in controls than in patients from the study group. Our findings do not provide a reasonable explanation for this discrepancy, and further research is required.

\section{Study limitations}

This study examined all patients with PE treated in a department of internal medicine, but did not investigate patients with PE diagnosed in other departments. D-dimer, conventional troponin $\mathrm{T}$, and highly sensitive troponin $\mathrm{T}$ levels were not routinely tested in all patients with PE, including those with malignancy. The differences in our descriptive results may be due to the age difference between the study population groups and individual biological variations with regard to limited life expectancy. Other limitations of this study were its small size (particularly that of the study group), its retrospective nature, and the fact that it was a single-center analysis.

\section{Conclusion}

An increased incidence of PE was not observed among the very elderly compared with the elderly. The clinical presentation of PE in the very elderly was subtle and there were no clear clinical symptoms in this group. Blood gas analyses were nonspecific, and D-dimer and troponin had minimal predictive value in this population. Further, there were no typical electrocardiographic changes, and an ideal radiological modality for diagnosing $\mathrm{PE}$ in the very elderly could not be identified.

\section{Disclosure}

The author reports no conflicts of interest in this work.

\section{References}

1. Hirsh J, Hoak J. Management of deep vein thrombosis and pulmonary embolism. A statement for healthcare professionals. Council on Thrombosis (in consultation with the Council on Cardiovascular Radiology), American Heart Association. Circulation. 1996;93:2212-2245.

2. Righini M, Le Gal G, Perrier A, Bounameaux H. The challenge of diagnosing pulmonary embolism in elderly patients: influence of age on commonly used diagnostic tests and strategies. J Am Geriatr Soc. 2005;53:1039-1045.

3. Weberová D, Weber P, Kubesová $\mathrm{H}$, et al. Occurrence of pulmonary embolism among 260 in-patients of acute geriatric department aged 65+ years in 2005-2010. Adv Gerontol. 2012;25:506-512.

4. Kniffin WD Jr, Baron JA, Barrett J, Birkmeyer JD, Anderson FA Jr. The epidemiology of diagnosed pulmonary embolism and deep venous thrombosis in the elderly. Arch Intern Med. 1994;154:861-866.

5. Rogers RL. Venous thromboembolic disease in the elderly patient: atypical, subtle, and enigmatic. Clin Geriatr Med. 2007;23:413-423.

6. Masotti L, Ray P, Righini M, et al. Pulmonary embolism in the elderly: a review on clinical, instrumental and laboratory presentation. Vasc Health Risk Manag. 2008;4:629-636.

7. Busby W, Bayer A, Pathy J. Pulmonary embolism in the elderly. Age Ageing. 1988;17:205-209.

8. Ceccarelli E, Masotti L, Barabesi L, Forconi S, Cappelli R. Pulmonary embolism in very old patients. Aging Clin Exp Res. 2003;15: 117-122.

9. Gisselbrecht M, Diehl JL, Meyer G, Collignon MA, Sors H. Clinical presentation and results of thrombolytic therapy in older patients with massive pulmonary embolism: a comparison with non-elderly patients. J Am Geriatr Soc. 1996;44:189-193.

10. Kokturk N, Oguzulgen IK, Demir N, Demirel K, Ekim N. Differences in clinical presentation of pulmonary embolism in older vs younger patients. Circ J. 2005;69:981-986.

11. Le Gal G, Righini M, Roy PM, et al. Differential value of risk factors and clinical signs for diagnosing pulmonary embolism according to age. J Thromb Haemost. 2005;3:2457-2464. 
12. Masotti L, Ceccarelli E, Cappelli R, Guerrini M, Forconi S. Pulmonary embolism in the elderly: clinical, instrumental and laboratory aspects. Gerontology. 2000;46:205-211.

13. Punukollu H, Khan IA, Punukollu G, Gowda RM, Mendoza C, Sacchi TJ. Acute pulmonary embolism in elderly: clinical characteristics and outcome. Int J Cardiol. 2005;99:213-216.

14. Ramos A, Murillas J, Mascías C, Carretero B, Portero JL. Influence of age on clinical presentation of acute pulmonary embolism. Arch Gerontol Geriatr. 2000;30:189-198.

15. Stein PD, Gottschalk A, Saltzman HA, Terrin ML. Diagnosis of acute pulmonary embolism in the elderly. J Am Coll Cardiol. 1991;18: 1452-1457.

16. Timmons S, Kingston M, Hussain M, Kelly H, Liston R. Pulmonary embolism: differences in presentation between older and younger patients. Age Ageing. 2003;32:601-605.

17. Chung T, Emmett L, Khoury V, et al. Atrial and ventricular echocardiographic correlates of the extent of pulmonary embolism in the elderly. J Am Soc Echocardiogr. 2006;19:347-1353.

18. Poli D, Antonucci E, Testa S, Cosmi B, Palareti G, Ageno W; The FCSA (Italian Federation of Anticoagulation Clinics). The predictive ability of bleeding risk stratification models in very old patients on VKA treatment for venous thromboembolism. Results of the Prospective Collaborative EPICA study. J Thromb Haemost. April 11, 2013. [Epub ahead of print.]

19. Jones JS, Van Deelen N, White L, Dougherty J. Alveolar-arterial oxygen gradients in elderly patients with suspected pulmonary embolism. Ann Emerg Med. 1993;22:1177-1181.
20. Harper PL, Theakston E, Ahmed J, Ockelford P. D-dimer concentration increases with age reducing the clinical value of the D-dimer assay in the elderly. Intern Med J. 2007;37:607-613.

21. Righini M, de Moerloose P, Reber G, Perrier A, Bounameaux H. Should the D-dimer cut-off value be increased in elderly patients suspected of pulmonary embolism? Thromb Haemost. 2001;85:744.

22. Giannitsis E, Müller-Bardorff M, Kurowski V, et al. Independent prognostic value of cardiac troponin $\mathrm{T}$ in patients with confirmed pulmonary embolism. Circulation. 2000;102:211-217.

23. Enea I, Ceparano G, Mazzarella G, Di Sarno R, Cangiano G, Busino CA. Biohumoral markers and right ventricular dysfunction in acute pulmonary embolism: the answer to thrombolytic therapy. Ital Heart J Suppl. 2004;5:29-35. Italian.

24. Righini M, Le Gal G, Perrier A, Bounameaux H. Effect of age on the assessment of clinical probability of pulmonary embolism by prediction rules. J Thromb Haemost. 2004;2:1206-1208.

25. Stein PD, Woodard PK, Weg JG, et al; PIOPED II investigators. Diagnostic pathways in acute pulmonary embolism: recommendations of the PIOPED II investigators. Am J Med. 2006;119:1048-1055.

26. Stein PD, Hull RD, Kayali F, Ghali WA, Alshab AK, Olson RE. Venous thromboembolism according to age: the impact of an aging population. Arch Intern Med. 2004;164:2260-2265.

27. Righini M, Goehring C, Bounameaux H, Perrier A. Effects of age on the performance of common diagnostic tests for pulmonary embolism. Am J Med. 2000;109:357-361.

28. Sakuma M, Nakamura M, Takahashi T, et al. Pulmonary embolism is an important cause of death in young adults. Circ J. 2007;71: 1765-1770.
Clinical Interventions in Aging

\section{Publish your work in this journal}

Clinical Interventions in Aging is an international, peer-reviewed journal focusing on evidence-based reports on the value or lack thereof of treatments intended to prevent or delay the onset of maladaptive correlates of aging in human beings. This journal is indexed on PubMed Central, MedLine, the American Chemical Society's 'Chemical Abstracts

\section{Dovepress}

Service' (CAS), Scopus and the Elsevier Bibliographic databases. The manuscript management system is completely online and includes a very quick and fair peer-review system, which is all easy to use. Visit http://www.dovepress.com/testimonials.php to read real quotes from published authors. 